\title{
A Comparative Study of Quality of Life and Coping Strategy in Depression and Obsessive Compulsive Disorder
}

\author{
Kunzes $^{1 *}$, Singh. R. ${ }^{2}$
}

\section{ABSTRACT}

Quality of life includes the physical, functional, social and emotional well being of an individual. Coping strategy is one's flexibility in using different strategies according to the multiple situational demands is sown in empirical research to have an overall reduction in observable stress (Sideridus, 2006). The poor quality of life is associated with depression and obsessive compulsive disorder. Thus, the present study aims to see the quality of life and copying strategies in depression and obsessive compulsive disorder. It consists of 30 participants purposively selected from government hospitals across Gandhinagar and Ahmedabad. The participants were assigned in two groups' i.e Depression (15) and OCD (15). The respondents were assessed using quality of life questionnaire, Y-BOCS severity scale, Beck depression inventory and coping strategy inventory which was administered individually. There is no significant difference between the two groups on Coping Strategies and Quality of Life. It is found that Cognitive Restructuring and Social Support are negatively correlated with Depression. There is significant negative correlation between Problem Focused Engagement, Emotion Focused Engagement, cognitive strategy, Engagement, Quality of Life with depression. Whereas it shows no significant correlation between OCD and coping strategy and OCD and Quality of Life.

Keywords: Coping Strategies, Quality of Life

Quality of life is defined as an individual's perception of their position in life in the context of the culture and value systems in which they live and in relation to their goals, expectations, standards and concerns. It is a broad ranging concept affected in a complex way by the person's physical health, psychological state, and level of independence, social relationships, and their relationship to salient features of their environment (WHO). Quality of life includes the physical, functional, social and emotional well being of an individual. On the other side, Coping involves

\footnotetext{
${ }^{1}$ M.Phil. Clinical Psychology, Institute of Behavioural Science, Gujarat Forensic Sciences University, Gandhinagar, Gujarat, India

${ }^{2}$ Lecturer, Institute of Behavioural Science, Gujarat Forensic Sciences University, Gandhinagar, Gujarat, India *Responding Author

(C) 2016 I Kunzes, R Singh; licensee IJIP. This is an Open Access Research distributed under the terms of the Creative Commons Attribution License (http://creativecommons.org/licenses/by/2.0), which permits unrestricted use, distribution, and reproduction in any Medium, provided the original work is properly cited.
} 


\section{A Comparative Study of Quality of Life and Coping Strategy in Depression and Obsessive Compulsive Disorder}

the decision of which behaviors to utilize to handle the event and it is an interaction between the person's internal resources and external environmental demands (Lazarus \& Folkman, 1984). Coping is conceptualized as efforts to ameliorate the perceived threat or to manage stress emotions (emotion-focused coping and problem-focused coping). Coping strategy is one's flexibility in using different strategies according to the multiple situational demands is shown in empirical research to have an overall reduction in observable stress (Sideridus, 2006).

Depression is characterized as persistent low mood, reduced interest in earlier pleasurable activities and reduced energy or fatigability, insomnia, low self confidence, worthlessness, hopelessness, death wishes or even suicidal attempts. These symptoms experienced for more than two weeks varying in severity level. It is one of the most common and leading cause of disability and life threatening, It is estimated to affect 350 million people globally (WHO, 2015). In India, there is high prevalence rate of late-life depression (Anisha Nakulan et al, 2015); Functional somatic symptoms are highly prevalent in Indian depressed patients (Sandeep Grover, 2013).

Obsessive Compulsive Disorder is classified in the ICD-10 as recurrent, repetitive and intrusive thoughts, images or impulses which is distressing and followed by an act of compulsions. Obsessive compulsive disorder (OCD) is a psychiatric disorder that often tends to run a chronic course. The subjects with affective or anxiety disorders who enter clinical trials have significant quality-of-life impairment, although the degree of dysfunction varies (Rapaport et al 2005) and measures of quality of life (QOL) in OCD represent important markers of well-being (Hauschildt and Moritz, 2011). The poor quality of life and coping strategy is associated with Depression and Obsessive Compulsive Disorder.

\section{LITERATURE REVIEW}

The studies have shown that coping strategies used in depression are mainly avoidant coping strategies and tends to show that QOL in Depression is usually low depending on Depression severity. Whereas on comparative perspective of coping strategy and Quality of Life in Depression and OCD gives a mix result. Similarly they also give a mix idea about whether or not coping Strategy and QOL has any correlation with OCD. Koran et al (1996) study suggest that the more severe the obsessive-compulsive disorder, the lower were the patients' social functioning scores. The ratings of the obsessive-compulsive disorder patients on physical health domains resembled those of the general population and exceeded those of the diabetes patients. The general health and physical health ratings of the obsessive-compulsive disorder patients exceeded those of the depressed patients. In mental health domains, after adjustment for differences in gender distribution, quality of life ratings were similar for the patients with obsessive-compulsive disorder and those with depressive disorders. Subramanian et al (2013) in their review study suggest that most studies indicate that those with OCD had diminished QOL 


\section{A Comparative Study of Quality of Life and Coping Strategy in Depression and Obsessive Compulsive Disorder}

across all domains relative to normative comparison subjects; they scored better on QOL domains than patients with major depressive disorder (MDD). Although research on sociodemographic correlates of QOL in OCD is largely contradictory, most studies suggest that symptom severity and comorbid depression or depressive symptoms are predictors of decreased QOL in OCD, with numerous studies showing this association across multiple domains associated with QOL. Mario Masellis et al (2003) study found that Obsession severity was found to significantly predict patient QOL and Comorbid depression severity was the single greatest predictor of poor QOL, accounting for $54 \%$ of the variance. In a review study by Srivastava and Bhatia (2007) on Quality of Life in Obsessive Compulsive Disorder they concluded that there are several aspects to the impairment of QOL in patients with OCD which include direct impairment of QOL by such means as loss of time to compulsive behaviours and impairment related to the social isolation. Sanjaya et al (2011), Compulsive hoarders had significantly lower levels of satisfaction with their safety, were much less satisfied with their living arrangements and have lower QOL than non-hoarding OCD patients in the domains of safety and living situation. Quality of Life deficits were not restricted to emotional and social aspects of Quality of Life but extended to somatic domains (Moritz et al, 2005), There is a significantly positive correlation between disease severity (YBOCS Score) and degree of suicidal ideation (SIS Score) in OCD (Mohan Dhyani et al, 2013). OCD patients share severely compromised well-being and QOL deficits were not restricted to emotional and social aspects of QOL but extended to somatic domains (Moritz, 2005). Hauschildt and Moritz (2011), repeatedly described consequences of

OCD in social, functional, and emotional fields, which often persist even after treatment, refer to the necessity to increasingly address these aspects in treatment planning. Macy et al (2013) results show that QOL in OCD is significantly impaired when compared to QOL in the general population and in patients with other psychiatric and medical disorders and appears to be largely affected by comorbid conditions.

Bystritsky et al (2001) study found that QOL were significantly lower for the OCD patients both before and after treatment, but improved significantly during treatment. Similarly, Papakostas et al (2004) review study on Quality of life assessments in major depressive disorder reports poorer quality of life in MDD patients compared to controls and that several studies have reported an improvement in quality of life measures during various phases of treatment with antidepressants and/or psychotherapy. Margaret Moore et al (2005) found that Depression and hopelessness were associated with a poorer present QOL, they had a larger gap between their actual present QOL and future (aspired to) QOL and Changes in QOL were influenced by depression and hopelessness. Angermeyer et al (2002) found that the shortly after discharge, quality of life of patients whose depression remitted was better than that of patients with persisting depression it was still slightly worse than that of the general population and even at the end of the follow-up period there was a slight lack of quality of life, especially as concerns the level of independence, spirituality/religion/personal beliefs and physical health. Kato (2015) his in study "The impact of

(c) The International Journal of Indian Psychology, ISSN 2348-5396 (e) | ISSN: 2349-3429 (p) | 140 


\section{A Comparative Study of Quality of Life and Coping Strategy in Depression and Obsessive Compulsive Disorder}

coping flexibility on the risk of depressive symptoms found that the proportions of women and men who reported depressive symptoms were $58.69 \%$ and $54.17 \%$, respectively and found that evaluation coping and adaptive coping were significantly associated with lower levels of depressive symptoms. In his another study (2015) he found that for all nationalities of American, Australian and Chinese and all genders, evaluation coping and adaptive coping were significantly correlated with lower levels of depressive symptoms. Structural equation modelling revealed that evaluation coping was associated with lower depressive symptoms for all nationalities and genders, whereas no significant relationships between adaptive coping and depressive symptoms were found for any nationalities. Chou et al (2011) study revealed that passive coping strategies mediated the relation between stress and depressive symptoms. Satija et al (1998) found that Depressive was using significantly more avoidance coping strategies as compared to non depressed. The moderate and severely depressed patient were exposed to more stressful life events and were using more avoidance coping strategies as compared to mildly depressed patients. Dyson and Renk (2006) suggest the levels of family and college stress reported by college students, as well as their endorsement of avoidant coping, significantly predicted their levels of depressive symptoms. Sugawara et al (2012), study suggest that in both genders, the highest odds ratios for avoidant coping strategy and the lowest odds ratios was associated with a problem-focused strategy after adjusting for covariates. After making the same adjustments, logistic regression analyses revealed that in both genders, the highest odds ratios were for emotional distraction coping strategies in relation to suicidal ideation. Nagase et al (2009), study that was aimed to examine the relation between depression and stress-coping strategy among the general population found that there was no marked gender difference in the prevalence of a problem-solving strategy, while various types of gender differences were found with respect to the prevalence of emotion-focused and avoidant strategies. In relation to depression, they found significantly highest odds ratios odds ratios for avoidant coping strategies and the lowest odds ratios for problem-focused ones in both genders. Najmi et al 2010, results suggest that high obsessive individuals in the non-clinical population are able to learn the futility of suppression through the thought suppression demonstration and to alter their faulty beliefs about the control of thoughts; however, for individuals with OCD, the demonstration may be insufficient for altering underlying beliefs.

\section{RESEARCH METHODOLOGY}

\section{Aim and Objectives:}

The present study aims to compare the quality of life and coping strategies in depression and obsessive compulsive disorder.

\section{Hypothesis:}

Ho1: There are no significant difference in the quality of life and coping strategy among the depressive and obsessive compulsive disorder patients. 


\section{A Comparative Study of Quality of Life and Coping Strategy in Depression and Obsessive Compulsive Disorder}

Ho2: There are no relationship between Depression, Coping Strategies and Quality of Life.

Ho3: There are no relationship between Obsessive Compulsive Disorder, Coping Strategies and Quality of Life.

\section{Population:}

The study population were recruited from the hospitals across Gandhinagar and Ahmedabad based on purposive sampling method including both males and females diagnosed with depression and OCD. The total sample size was 30 (15 depressions and 15 OCD).

\section{Study Design:}

This is a cross-sectional between group study.

\section{Inclusion Criteria:}

- $\quad$ Patients who are diagnosed with Depression and Obsessive Compulsive Disorder according to ICD-10 classification.

- $\quad$ Age between 18 to 65years

- $\quad$ Both male and female

- $\quad$ Participant who were willing to participate.

\section{Exclusion Criteria:}

- $\quad$ Presence of any other psychiatric condition

- $\quad$ Participate who were not willing to participate.

- $\quad$ Below 18yrs of age and above 65yrs

\section{Tools:}

The data were collected through self-administrated questionnaire and it included sociodemographic characteristics.

The tools that would be used:

- Quality of life Questionnaire: WHO Quality of Life-BREF is a self administer questionnaire consisting of 26 items, attempt to develop a quality of life assessment that would be applicable cross-culturally. It measures four domains of QOL: physical, psychological, social and environment. The WHOQOL-BREF is a shorter version of the original instrument WHOQOL-100.

- Beck Depression Inventory: Comprising of 21 questions for measuring severity of depression. The BDI is a widely used self-rated instrument with good psychometric properties: BDI scores correlate strongly with the number of threshold symptoms as assessed by the Structural Clinical Interview for the Diagnostic and Statistical Manual of Mental Disorders, Fourth Edition (DSM-IV), demonstrating the questionnaire’s construct validity. 


\section{A Comparative Study of Quality of Life and Coping Strategy in Depression and Obsessive Compulsive Disorder}

- $\quad$ YBOCS Severity: consisting of 10 questions for severity of obsession and compulsion. The Y-BOCS (Goodman et al., 1989 a; Goodman, Price, Rasmussen, \& Mazure, 1989b) is a 10item semi-structured clinician administered measure of obsession and compulsion severity. Each item addresses self-reported experiences in the last week. Questions are rated on a five-point Likert scale ranging from $0-4$, with higher scores representing greater symptom severity.

- $\quad$ Coping Strategy Inventory (revised 1984), consisting of 72 items self report questionnaire and a 5 item Likert format. The alpha coefficient for the CSI from .71 to .94. There are total of 14 subscales on the CSI including eight primary scales, four secondary scales and two tertiary scales. The scale is designed to assess coping thoughts and behavior in response to a particular stressor.

\section{Procedure:}

The study consisted of 30 samples divided into two groups of 15 each. After taking consent, tools were administered on each of the participants.

\section{Statistical Analysis:}

SPSS .20 versions is used for statistical analysis.

\section{RESULTS}

\section{Table 1. Characteristics of Participants.}

\begin{tabular}{|l|l|l|l|l|}
\hline S.No. & Variables & & Frequency & Percentage \\
\hline 1 & Gender & Male & 14 & 46.7 \\
\hline & & Female & 16 & 53.3 \\
\hline 2 & Marital Status & Unmarried & 8 & 26.7 \\
\hline & & Married & 20 & 66.7 \\
\hline 3 & & Divorced/Single & 2 & 6.7 \\
\hline & Education & Illiterate & 4 & 13.3 \\
\hline & & $<5$ th class & 4 & 13.3 \\
\hline & & $5>10$ th class & 8 & 26.7 \\
\hline & & $10>12$ th class & 5 & 16.7 \\
\hline & & Graduate & 8 & 26.7 \\
\hline 4 & Occupation & Post Graduate & 1 & 3.3 \\
\hline & & Non working (student/Housewife/ & 14 & 46.7 \\
\hline & & retired) & & 23.3 \\
\hline 5 & Delf Employed & 7 & 30 \\
\hline & & Govt or Private Organization & 9 & 6.7 \\
\hline & & Normal range (0-9) & 2 & 13.3 \\
\hline
\end{tabular}

(C) The International Journal of Indian Psychology, ISSN 2348-5396 (e)| ISSN: 2349-3429 (p) | 143 
A Comparative Study of Quality of Life and Coping Strategy in Depression and Obsessive Compulsive Disorder

\begin{tabular}{|l|l|l|l|l|}
\hline S.No. & Variables & & Frequency & Percentage \\
\hline & & Moderate-severe(20-29) & 4 & 13.3 \\
\hline & & Severe Depression(30-63) & 5 & 16.7 \\
\hline 6 & OCD & Mild(8-15) & 3 & 10.0 \\
\hline & & Moderate (16-23) & 3 & 10.0 \\
\hline & & Severe (24-31) & 9 & 30.0 \\
\hline
\end{tabular}

The table showing that study comprised of both males (53.3\%) and females (46.7\%). Most of them were married (66.7\%), educated between standard $5^{\text {th }}$ and $10^{\text {th }}$ or graduates (both $26.7 \%$ ), non working (46.7\%), 16.7 having severe Depression and 30\% with severe Obsession Compulsive Disorder.

Table 2. Mean age of the sample.

\begin{tabular}{|l|l|l|l|l|}
\hline S.No & Variable & N & Mean & Std Deviation \\
\hline 1 & Age & 30 & 29 & 1.65 \\
\hline
\end{tabular}

The Mean age of the sample was 29 yrs with standard deviation of 1.6

Table 3. Comparing COPING STRATEGY and QUALITY OF LIFE among Depression and Obsessive Compulsive Disorder.

\begin{tabular}{|l|l|l|}
\hline Domains & t & Sig. (2-tailed) \\
\hline Problem Solving & 0.29 & 0.77 \\
\hline Cognitive Restructuring & -0.08 & 0.93 \\
\hline Social Support & 1.50 & 0.14 \\
\hline Expressed Emotions & 0.86 & 0.39 \\
\hline Problem Avoidance & 1.81 & 0.08 \\
\hline Wishful Thinking & -0.94 & 0.35 \\
\hline Self Criticism & -1.27 & 0.21 \\
\hline Social Withdrawal & 1.10 & 0.28 \\
\hline Problem Focused Engagement & 0.10 & 0.91 \\
\hline Emotion Focused Engagement & 1.35 & 0.18 \\
\hline Problem Focused Disengagement & 0.38 & 0.70 \\
\hline Emotion Focused Disengagement & -0.32 & 0.74 \\
\hline COPE Engagement & 0.76 & 0.45 \\
\hline COPE Disengagement & 0.03 & 0.97 \\
\hline QOL Physical Health & -0.11 & 0.90 \\
\hline QOL Psychological & -0.01 & 0.98 \\
\hline QOL Social Relationship & -.19 & .85 \\
\hline QOL Environment & -.35 & .72 \\
\hline
\end{tabular}

(c) The International Journal of Indian Psychology, ISSN 2348-5396 (e)| ISSN: 2349-3429 (p) | 144 
A Comparative Study of Quality of Life and Coping Strategy in Depression and Obsessive Compulsive Disorder

Table 3 showing no significant difference between the two groups on Coping Strategies and Quality of Life.

Table 4. Pearson Correlation between Depression (1) and Coping and Quality of Life.

\begin{tabular}{|l|l|l|l|}
\hline S.no & Variables & Pearson Correlation & Sig. (2-tailed) \\
\hline 1 & Problem Solving & -0.49 & 0.06 \\
\hline 2 & Cognitive Restructuring & $-.56^{*}$ & 0.02 \\
\hline 3 & Social Support & $-.58^{*}$ & 0.02 \\
\hline 4 & Expressed Emotions & -0.39 & 0.14 \\
\hline 5 & Problem Avoidance & -0.12 & 0.66 \\
\hline 6 & Wishful Thinking & 0.05 & 0.85 \\
\hline 7 & Self Criticism & 0.35 & 0.19 \\
\hline 8 & Social Withdrawal & 0.34 & 0.21 \\
\hline 9 & Problem Focused Engagement & $-.54^{*}$ & 0.03 \\
\hline 10 & Emotion Focused Engagement & $-.65^{* *}$ & 0.00 \\
\hline 11 & Problem Focused Disengagement & -0.04 & 0.87 \\
\hline 12 & Emotion Focused Disengagement & 0.45 & 0.08 \\
\hline 13 & COPE Engagement & $-.61^{*}$ & 0.01 \\
\hline 14 & COPE Disengagement & 0.30 & 0.27 \\
\hline 15 & QOL Physical Health & $-.63^{*}$ & 0.01 \\
\hline 16 & QOL Psychological & $-.69^{* *}$ & 0.00 \\
\hline 17 & QOL Social Relationship & $-.86^{* *}$ & 0 \\
\hline 18 & QOL Environment & $-.81^{* *}$ & 0 \\
\hline Correl| & ion is Signficant the & \\
\hline
\end{tabular}

Correlation is significant at the 0.05 level (2-tailed).*

Correlation is significant at the 0.01 level (2-tailed).**

Table 4. Showing that Cognitive Restructuring, Social Support, Problem Focused Engagement, Emotion Focused Engagement, tertiary subscales of cognitive strategy (Engagement) are significantly negatively correlated (-.56, -.58, -.54, -.65 and -.61 respectively) with Depression. All domains of Quality of Life Physical Health, Psychological health, Social Relationship and Environment is significantly negatively correlated with depression as -.63, -.69, -.86 and -.81 respectively).

(c) The International Journal of Indian Psychology, ISSN 2348-5396 (e)| ISSN: 2349-3429 (p) | 145 
A Comparative Study of Quality of Life and Coping Strategy in Depression and Obsessive Compulsive Disorder

Table 5. Pearson Correlation between Obsession Compulsive Disorder (1) and Coping and Quality of Life.

\begin{tabular}{|l|l|l|l|}
\hline S.no & Variables & Pearson Correlation & Sig.(2-tailed) \\
\hline 1. & Problem Solving & -0.26 & 0.34 \\
\hline 2 & Cognitive Restructuring & 0.08 & 0.76 \\
\hline 3 & Social Support & -0.19 & 0.48 \\
\hline 4 & Expressed Emotions & -0.13 & 0.64 \\
\hline 5 & Problem Avoidance & 0.19 & 0.47 \\
\hline 6 & Wishful Thinking & 0.14 & 0.60 \\
\hline 7 & Self Criticism & -0.13 & 0.63 \\
\hline 8 & Social Withdrawal & 0.33 & 0.21 \\
\hline 9 & Problem Focused Engagement & -0.10 & 0.70 \\
\hline 10 & Emotion Focused Engagement & -0.16 & 0.55 \\
\hline 11 & Problem Focused Disengagement & -0.10 & 0.70 \\
\hline 12 & Emotion Focused Disengagement & 0.09 & 0.74 \\
\hline 13 & COPE Engagement & -0.16 & 0.55 \\
\hline 14 & COPE Disengagement & 0.24 & 0.38 \\
\hline 15 & QOL Physical Health & 0.08 & 0.77 \\
\hline 16 & QOL Psychological & -0.17 & 0.54 \\
\hline 17 & QOL Social Relationship & -0.32 & 0.24 \\
\hline 18 & QOL Environment & 0.18 & 0.52 \\
\hline
\end{tabular}

Correlation is significant at the 0.05 level (2-tailed).*

Correlation is significant at the 0.01 level (2-tailed).**

Table 5, shows no significant correlation between OCD and coping strategy and OCD and Quality of Life.

\section{DISCUSSION}

The present study aims to see the quality of life and copying strategies in Depression and Obsessive Compulsive Disorder with total sample size of 30 participants (15 Depression and 15 OCD). The study comprised of both males (53.3\%) and females (46.7\%). Most of them were married (66.7\%), educated between standard $5^{\text {th }}$ and $10^{\text {th }}$ or graduates (both $26.7 \%$ ), non working (46.7\%), 16.7 having severe Depression and 30\% with severe Obsession Compulsive Disorder (Table 1). The Mean age of the sample is 29 yrs with standard deviation of 1.6 (Table 2).

It is found that there is no significant difference between the two groups on Coping Strategies and Quality of Life (Table 3). Thus accepting the stated hypothesis Ho1. Karan et al (1996) also

(c) The International Journal of Indian Psychology, ISSN 2348-5396 (e)| ISSN: 2349-3429 (p) | 146 


\section{A Comparative Study of Quality of Life and Coping Strategy in Depression and Obsessive Compulsive Disorder}

suggest that Quality of Life in patients with OCD and Depression was similar. Whereas Subramanian et all (2013), showed that patient with OCD scored better on Quality of Life domains than patients with Major depressive disorder.

Secondly, It is found that Cognitive Restructuring and Social Support are negatively correlated negatively (-.56 and -.58) with Depression ( $P$ value at 0.05 levels) indicating that increase in depression will decrease cognitive restructuring and social support as shown in Table 4. Gençöz et al (2001), study that was done to assess information processing in depression showed lower rates of positive adjective endorsement and lower rates of positive adjective recall were found to be associated with depression. Prince et al (1997), showed similar result that there was a stronger, graded, relationship between the number of social support deficits and depression. Loneliness was itself strongly associated with depression. Paykel (1994), review paper found that for social support there are greater problems in the extent to which social support may be determined by the individual's own behavior. Absence of social support appears to be associated with onset and relapse of depression, both acting independently and modifying effects of life events. Timbremont and Braet (2004) indicated that the depressed and the remitted depressed groups rated more negative words more self-descriptive than the never depressed group; the never depressed group showed positive information processing compared to the depressed and the remitted depressed groups.

The correlation between Problem Focused Engagement and Depression is -.54 significant at .03 ( $\mathrm{P}$ value at 0.05 levels) and Emotion Focused Engagement is -.65 significant at .008 (P value at $0.01)$. On the tertiary subscales of cognitive strategy, Engagement is negatively correlated (-.61) with Depression at 0.014 (P value at 0.05 levels). Matthew (2014) found that among neverdepressed individuals, less primary control coping (e.g., problem-solving) and greater disengagement coping (e.g., avoidance) predicted increases in depressive symptoms. Studies have shown more avoidance coping strategies in Depression (Satija et al, 1998, Dyson and Renk 2006, Sugawara et al 2012 and Nagase et al 2009).

All domains of Quality of Life Physical Health, Psychological health, Social Relationship and Environment is significantly negatively correlated with depression as -..63, -.69, -.86 and -.81 respectively). Physical Health significant at .011 level (P value at 0.05 ) and Psychological Health, Social Relationship and Environment significant at 0.004, 0 and 0 (P value at 0.01 level) similar study by Puig-Antich et al (1993) found Adolescents with MDD have severe difficulties in all areas of psychosocial functioning and family environment.

Thirdly, on Table 5, it shows no significant correlation was found between OCD and coping strategy and OCD and Quality of Life, therefore the stated hypothesis Ho3 is accepted. Our Study showing no significant correlation between OCD and coping strategy and OCD and 


\section{A Comparative Study of Quality of Life and Coping Strategy in Depression and Obsessive Compulsive Disorder}

Quality of Life could be because most of the patients with OCD were undergoing pharmacological and psychotherapeutic treatment. Studies have been In contrast to our findings for QOL and coping in OCD, a review study by Srivastava and Bhatia (2008) on Quality of Life in Obsessive Compulsive Disorder found that there are several aspects to the impairment of QOL in patients with OCD, Lebowitz et al (2012) found that family accommodation is common in OCD and is strongly and consistently correlated with OCD symptom severity and Rampacher et al (2010) suggested that the patients with OCD were impaired in problem solving.

\section{LIMITATION AND FUTURE SUGGESTIONS}

The present study had small size so it can be suggested that a study can take larger sample size in future. Secondly it can be suggested that other psychiatric conditions can also be compared.

\section{CONCLUSION}

The present study aimed to see the quality of life and coping strategies in depression and obsessive compulsive disorder reveals that there is no significant difference between Depression and OCD on Coping Strategies and Quality of Life. It is found that Cognitive Restructuring and Social Support are significantly negatively correlated with Depression. There is significant negative correlation between Problem Focused Engagement, Emotion Focused Engagement and Depression. On the tertiary subscales of cognitive strategy, Engagement is negatively correlated with Depression. Quality of life is significantly negatively correlated with depression but it shows no significant correlation between OCD and coping strategy and OCD and Quality of Life.

\section{REFERENCES}

Anisha Nakulan, TP Sumesh” Sebind Kumar, PP Rejani' KS Shaji Prevalence and risk factors for depression among community resident older people in Kerala. Indian journal of psychiatry Year : 2015, Volume : 57, Issue : 3, 262-266.

Bystritsky A, Liberman RP, Hwang S, Wallace CJ, Vapnik T, Maindment K, Saxena S. Social functioning and quality of life comparisons between obsessive-compulsive and schizophrenic disorders. Depress Anxiety. 2001;14(4):214-8.

Chou PC, Chao YM, Yang HJ, Yeh GL, Lee TS. Relationships between stress, coping and depressive symptoms among overseas university preparatory Chinese students: a crosssectional study. BMC Public Health. 2011 May 19;11:352. doi: 10.1186/1471-2458-11-352.

Dyson R, Renk K. Freshmen adaptation to university life: depressive symptoms, stress, and coping. J Clin Psychol. 2006 Oct; 62(10):1231-44.

Gençöz T, Voelz ZR, Gençöz F, Pettit JW, Joiner TE Jr. Specificity of information processing styles to depressive symptoms in youth psychiatric inpatients. J Abnorm Child Psychol. 2001 Jun; 29(3):255-62.

(c) The International Journal of Indian Psychology, ISSN 2348-5396 (e)| ISSN: 2349-3429 (p) | 148 


\section{A Comparative Study of Quality of Life and Coping Strategy in Depression and Obsessive Compulsive Disorder}

Hauschildt M, Moritz S Obsessive-compulsive disorder: psychosocial consequences and quality of life: a review. Nervenarzt. 2011 Mar;82(3):281-2, 284, 286, passim. doi: 10.1007/s00115-010-2961-4.

Kato $\mathrm{T}$ The impact of coping flexibility on the risk of depressive symptoms. PLoS One. 2015 May 26;10(5):e0128307. doi: 10.1371/journal.pone.0128307. eCollection 2015.

Kato $\mathrm{T}$. Testing of the coping flexibility hypothesis based on the dual-process theory: Relationships between coping flexibility and depressive Symptoms. Psychiatry Res. 2015 Dec 15;230(2):137-42. doi: 10.1016/j.psychres.2015.07.030. Epub 2015 Jul 15.

Koran LM, Thienemann ML, Davenport R. Quality of life for patients with obsessivecompulsive disorder. Am J Psychiatry. 1996 Jun;153(6):783-8.

Lebowitz ER, Panza KE, Su J, Bloch MH. Family accommodation in obsessive-compulsive disorder.Expert Rev Neurother. 2012 Feb;12(2):229-38. doi: 10.1586/ern.11.200.

M. C. Angermeyer, A. Holzinger, H. Matschinger, K. Stengler-Wenzke study on Depression and Quality of Life: Results of a Follow-Up Study. International Journal of Social Psychiatry September 2002 vol. 48 no. 3 189-199. doi: 10.1177/002076402128783235

Macy AS, Theo JN, Kaufmann SC, Ghazzaoui RB, Pawlowski PA, Fakhry HI, Cassmassi BJ, IsHak WW Quality of life in obsessive compulsive disorder. CNS Spectr. 2013 Feb; 18(1):21-33. doi: 10.1017/S1092852912000697. Epub 2013 Jan 2.

Margaret Moore, Stefan Höfer, Hannah McGee and Lena Ring. Can the concepts of depression and quality of life be integrated using a time perspective? Health and Quality of Life Outcomes20053:1 DOI: 10.1186/1477-7525-3-1

Mario Masellis, MD, MSc, Neil A Rector, PhD, Margaret A Richter, MD Quality of Life in OCD: Differential Impact of Obsessions, Compulsions, and Depression Comorbidity, Can J Psychiatry 2003; 48:72-77

Matthew C. Morris, Lindsay D. Evans, Uma Rao, and Judy Garber, Executive Function Moderates the Relation between Coping and Depressive Symptoms. Published online 2014 Jun 17. doi: 10.1080/10615806.2014.925545

Mohan Dhyani, Jitendra Kumar Trivedi, Anil Nischal, Pramod Kumar Sinha, Subham Verma. Suicidal behaviour of Indian patients with obsessive compulsive disorder India. DOI: 10.4103/0019-5545.111455. Year : 2013, Volume : 55, Issue : 2, Page : 161-166

Moritz S, Rufer M, Fricke S, Karow A, Morfeld M, Jelinek L, Jacobsen D. Quality of life in obsessive-compulsive disorder before and after treatment. Compr Psychiatry. 2005 NovDec;46(6):453-9.

Nagase Y, Uchiyama M, Kaneita Y, Li L, Kaji T, Takahashi S, Konno M, Mishima K, Nishikawa T, Ohida T. Coping strategies and their correlates with depression in the Japanese general population. Psychiatry Res. 2009 Jun 30;168(1):57-66. doi: 10.1016/j.psychres.2008.03.024. Epub 2009 May 18. 


\section{A Comparative Study of Quality of Life and Coping Strategy in Depression and Obsessive Compulsive Disorder}

Najmi S, Reese H, Wilhelm S, Fama J, Beck C, Wegner DM. Learning the futility of the thought suppression enterprise in normal experience and in obsessive compulsive disorder. Behav Cogn Psychother. 2010 Jan;38(1):1-14. doi: 10.1017/S1352465809990439. Epub 2009 Oct 26.

Papakostas GI, Petersen T, Mahal Y, Mischoulon D, Nierenberg AA, Fava M: Quality of life assessments in major depressive disorder: a review of the literature. Gen Hosp Psychiatry 2004, 26: 13-17.10.1016/j.genhosppsych.2003.07.004PubMedView Article

Paykel ES Life events, social support and depression. Acta Psychiatr Scand Suppl. 1994; 377:50-8.

Prince MJ, Harwood RH, Blizard RA, Thomas A, Mann AH.Psychol Med. Social support deficits, loneliness and life events as risk factors for depression in old age. The Gospel Oak Project VI.1997 Mar; 27(2):323-32.

Puig-Antich J, Kaufman J, Ryan ND, Williamson DE, Dahl RE, Lukens E, Todak G, Ambrosini P, Rabinovich H, Nelson BJ Am Acad Child Adolesc Psychiatry. The psychosocial functioning and family environment of depressed adolescents.1993 Mar;32(2):244-53.

Rampacher F, Lennertz L, Vogeley A, Schulze-Rauschenbach S, Kathmann N, Falkai P, Wagner M. Evidence for specific cognitive deficits in visual information processing in patients with OCD compared to patients with unipolar depression. Prog Neuropsychopharmacol Biol Psychiatry. 2010 Aug 16;34(6):984-91. doi: 0.1016/j.pnpbp.2010.05.008. Epub 2010 May 18.

Rapaport MH, Clary C, Fayyad R, Endicott J. Quality-of-life impairment in depressive and anxiety disorders. Am J Psychiatry. 2005 Jun;162(6):1171-8.

Sandeep Grover, Ajit Avasthi, Kamal Kalita, PK Dalal, GP Rao, RK Chadda, Bhavesh Lakdawala, Govind Bang, Kaustav Chakraborty, Sudhir Kumar, PK Singh, Puneet Kathuria, M Thirunavukarasu, P. S. V. N. Sharma, T Harish, Nilesh Shah, Kamla Deka: Functional somatic symptoms in depression, Year : 2013, Volume : 55, Issue : 1, Page : 31-40. DOI: 10.4103/0019-5545.105502

Sanjaya Saxena, Catherine R. Ayers. Karron M. Maidment, Tanya Vapnik, Julie L. Wetherell and Alexander Bystritsky. Quality of Life and Functional Impairment in Compulsive Hoarding. J Psychiatr Res. 2011 Apr; 45(4): 475-480.

Srivastava S, Bhatia M.S. Quality of Life in Obsessive Compulsive Disorder - A Brief Review. Delhi Psychiatry Journal Vol. 11 No.2

Subramaniam M, Soh P, Vaingankar JA, Picco L, Chong SA. CNS Drugs. 2013 Quality of life in obsessive-compulsive disorder: impact of the disorder and of treatment. May; 27(5):36783. doi: 10.1007/s40263-013-0056-z.

Sugawara N, Yasui-Furukori N, Sasaki G, Tanaka O, Umeda T, Takahashi I, Iwane K, Matsuzaka M, Kaneko S, Nakaji S. Coping behaviors in relation to depressive symptoms and suicidal ideation among middle-aged workers in Japan. J Affect Disord. 2012 Dec 15;142(1-3):264-8. doi: 10.1016/j.jad.2012.05.011. Epub 2012 Jul 24.

Timbremont and Braet, Congnitive Vulnerability in remitted depressed children and adolescent. Bethaviour Research and Therapy 42 (2004) 423-437. Elsevier Ltd:doi: 10.1016/S00057967(03)00151-7. 


\section{A Comparative Study of Quality of Life and Coping Strategy in Depression and Obsessive Compulsive Disorder}

Y.k Satija, G.B Advani and SS Nathawar. Influence of stressful life events and coping strategies in Depression. Indian journal of Psychiatry,1998, 40(2), 165-171.

YK Satija, GB Advani, SS Nathawat. Influence of Stressful Life Events and Coping Strategies in Depression, Indian journal of psychiatry Year : 1998 | Volume : 40 | Issue : 2 | Page : $165-171$

How to cite this article: Kunzes, R Singh (2016), A Comparative Study of Quality of Life and Coping Strategy in Depression and Obsessive Compulsive Disorder, International Journal of Indian Psychology, Volume 3, Issue 3, No. 11, DIP: 18.01.204/20160303, ISBN: 978-1-36521307-6

(c) The International Journal of Indian Psychology, ISSN 2348-5396 (e)| ISSN: 2349-3429 (p) | 151 